\title{
DESIGN OF A HIGH CAPACITY DERRICK CRANE CONSIDERING THE EFFECTS INDUCED BY LOAD APPLICATION AND RELEASE
}

\author{
Luigi Solazzi* \\ University of Brescia, department of mechanical and industrial engineering, Italy \\ Nenad Zrnić \\ Faculty of Mechanical Engineering, Belgrade, Serbia
}

The main object of this paper is to design a very big derrick crane (the main boom is $80 \mathrm{~m}$ in length and the payload is $60 \mathrm{t}$ ) considering the dynamical effects induced by moving a load. The research was developed through analytical calculation models for the preliminary design of the crane; subsequently many different finite element model analyses (FEM) were performed in order to evaluate the dynamical behavior of the crane. For this purpose different moving load patters were implemented in the numerical analyses in order to study the dynamical response of the crane in time. The numerical results show that the dynamical actions induced by sudden load release are much higher than those induced by using the crane in normal load conditions and that the magnitude of these actions are correlated to the geometrical crane configurations. The results also show that the buckling phenomenon is the most critical point of view for this type of crane and it justifies the collapse of the boom in a similar crane.

Key words: Moving loads, Dynamics effects, Dynamic load, Dynamical behavior, Modal analyses, Finite element method, Derrick crane, Lifting equipment

\section{INTRODUCTION}

Derrick cranes are special stationary cranes, mainly used for handling heavy loads. These type of cranes are generally used in the marine sector (on ships for example), in the construction industry, in the material handling field, etc. [10]. In particular, the crane object of this research finds application in quarries for the extraction of marble. Some basic elements that compose the crane are a column, two tie-rods that keep the column in vertical position and a boom (Figure 1) they are generally made by truss structures [10]. Other elements in the machine are a hoist hook, ropes for moving the load and the boom, engines, gearboxes, drums and brakes for moving the load in vertical direction and the boom in vertical and horizontal plane.

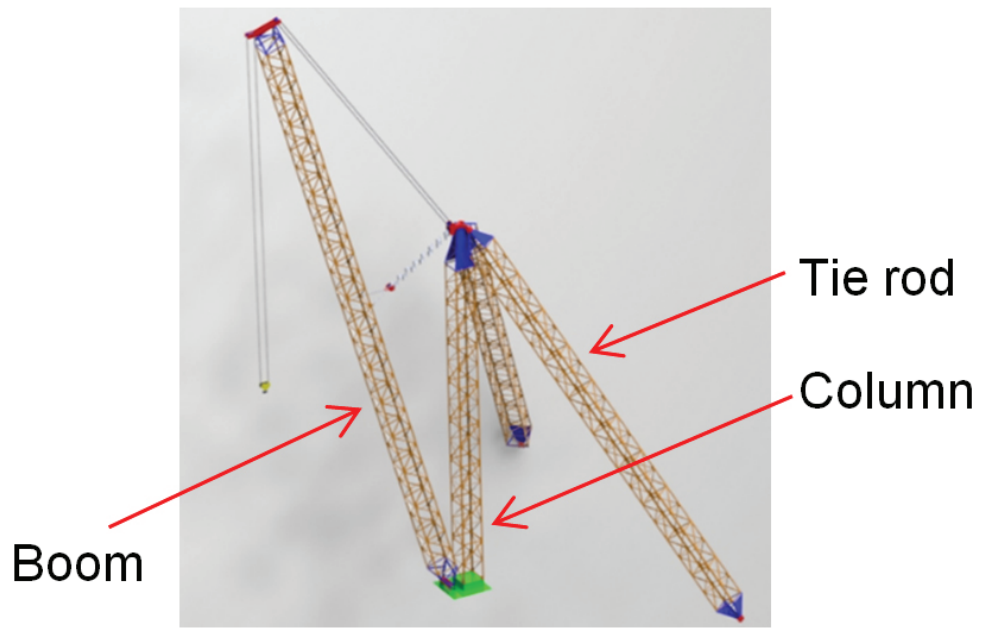

Figure 1: Design of the main components 
This work starts from the research developed to define the causes of failure of a crane boom, similar to the one under study. The size of this boom, which is the biggest available on the market, is equal to $75 \mathrm{~m}$ in length and the maximum magnitude of the payload equal to $50 \mathrm{t}$.
The pictures in Figure 2 show the failure of the boom. The analyses carried out showed that it collapsed due to buckling phenomena in the transverse plane (not in the vertical one). The pictures show the evident failure of the boom and how it laid down on the mountainside.

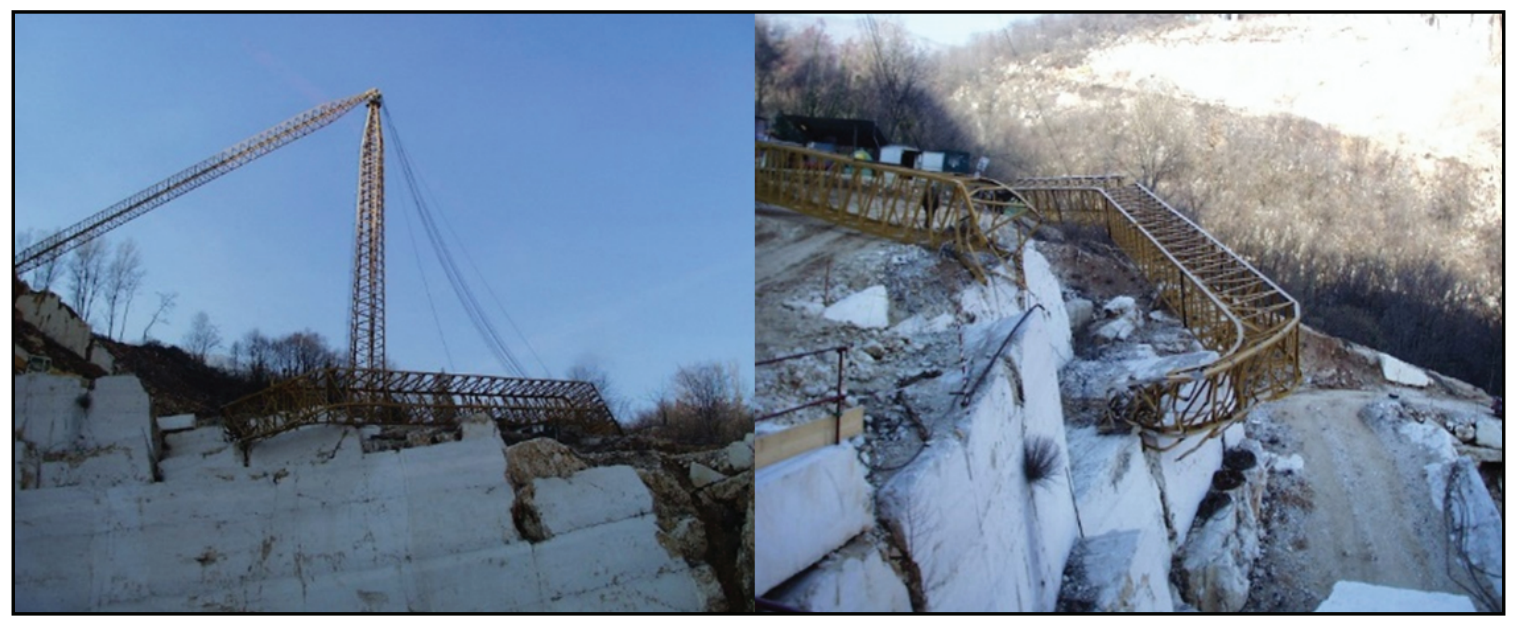

Figure 2: The collapsed boom of the derrick crane

\section{DESIGN SPECIFICATIONS}

The biggest derrick crane available on the market has a boom equal to $75 \mathrm{~m}$ in length and a payload equal to $50 \mathrm{t}$. In particular, the load chart shows a constant payload (approximately $25 \div 30$ t) for a boom inclination (respect to the horizontal plane) variable from $0^{\circ}$ to $30^{\circ}$ and a payload equal to $50 \mathrm{t}$ with an angle variable from $30^{\circ}$ to $85^{\circ}$. This crane is equipped with a tower whose height is approximately between $30 \mathrm{~m}$ and $40 \mathrm{~m}$, while the two lateral tie rods generally have an inclination of $45^{\circ}$ to $60^{\circ}$; this value is correlated to the installation area of the crane.
The crane specifications considered in this work are a boom equal to $80 \mathrm{~m}$ in length and a payload equal to $40 \mathrm{t}$ when the boom inclination is between $0^{\circ}$ and $30^{\circ}$, while the payload is equal to $60 \mathrm{t}$ for an inclination of the boom between $30^{\circ}$ and $85^{\circ}$ (Figure 3 ). The height of the tower is a variable design because it determines the main actions on the boom (axial and bending), while the inclination of the two tie rods is $60^{\circ}$. The load hoisting speed is $v_{s}=5 \mathrm{~m} / \mathrm{min}$; while the boom hoisting speed (defined at the top end of the boom) is: $v_{a}=5 \mathrm{~m} / \mathrm{min}$.

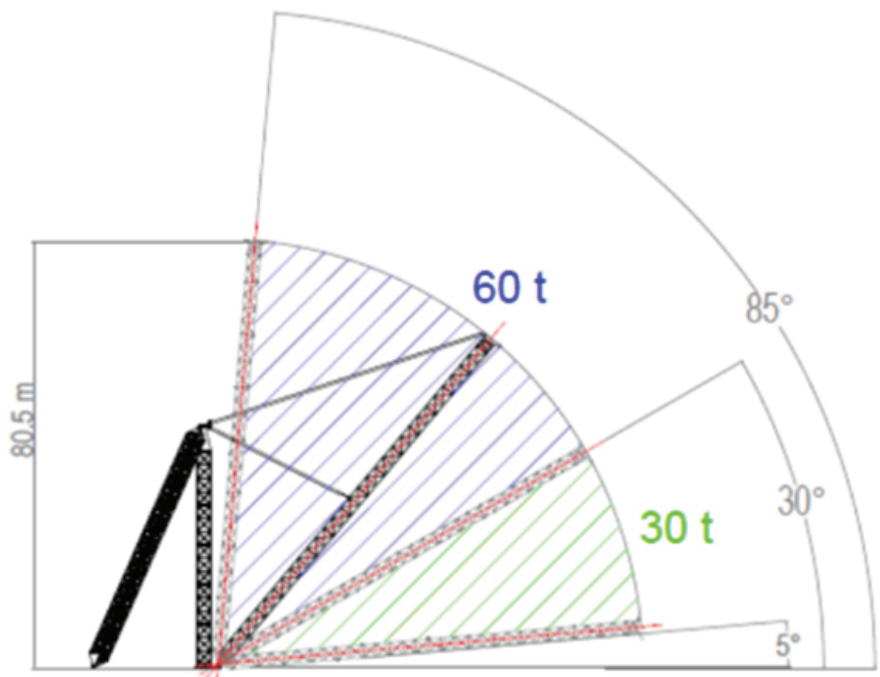

Figure 3: The load chart of the derrick crane 
The first steps of dimensioning included the development of calculation models to assess the actions of the load on the main elements of the derrick crane taking into account both the crane size and the load chart. A very important parameter in this phase of designing is the height of the tower, which is correlated to the axial and bend-

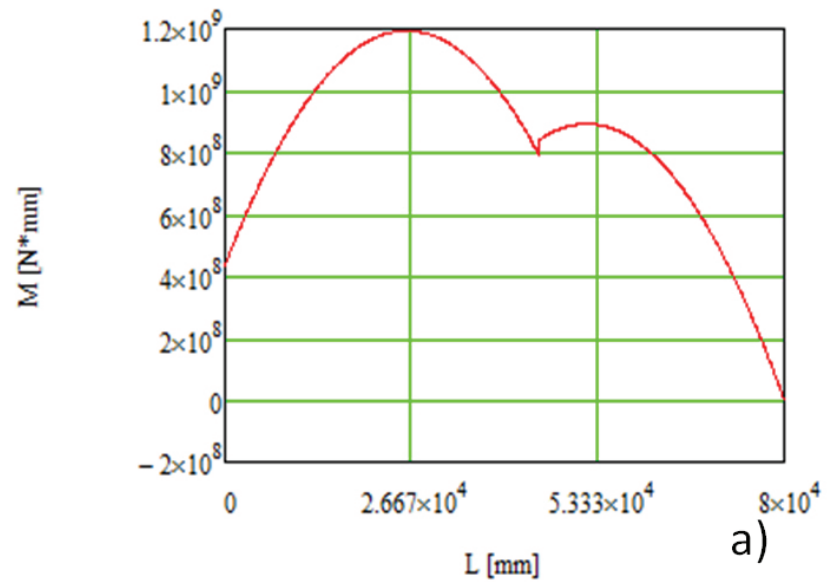

ing actions on the boom. Figure 4 shows the axial and bending actions diagram in the boom. It is important to underline that at the top of the boom $(x=0 \mathrm{~mm})$ the bending action is not equal to zero due to the eccentricity of the load applied by pulleys.

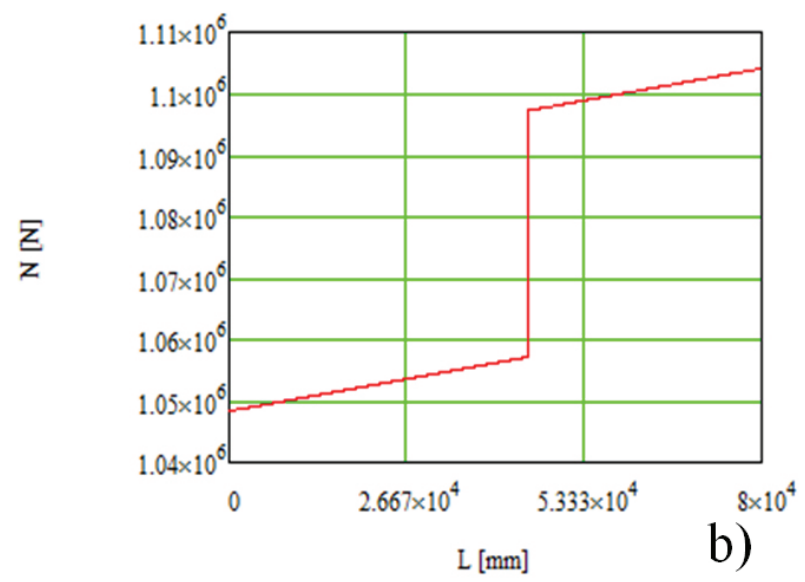

Figure 4: Bending action (a) and axial action (b) diagrams for the boom with the angle respect to the horizontal plane equal to $5^{\circ}$

By means of some numerical analyses, it was decided to adopt a $45 \mathrm{~m}$ high tower and two 55 $\mathrm{m}$ length tie-rods. The next step was to design the reticular structures which represent the fundamental elements. The technological and economic aspects received serious consideration in the design stage. First of all it is important to observe that the boom, the tie rods and the tower must be transported by suitable vehicles to the place where the crane will be installed. This implies that the weight of the individual blocks as well as their dimensions must comply with the Highway Code. The structure cannot be built in the quarry, as it is located in an inaccessible place (usually a mountainside) and without reference plans. The design of the same modular structure for tie rods, tower and boom meet the requirements stated above and allows standardization of the procurement and construction processes in the best way possible. Each module, which will be assembled in the quarry by means of a bolted joint, has the following dimensions: 5 $\mathrm{m}$ length and $2.6 \times 2.6 \mathrm{~m}$ cross-section.

Specific modules constitute the ends of the boom, the tower and the two tie rods. For example, the module of the tie rod at one side must interface with the foundation plinth, while at the other side it must interface with the upper of the tower. The size of the truss structures is calculated analytically adopting two classical theories: the method of sections or Ritter's method and the method of joints i.e. equilibrium at nodes $/ 3 /$. It is important to note that these theories are approximated as a consequence of the fact that, for instance, the elements forming the truss structure are considered slender and so the bending action is not considered. Actually the structure is made up of angular elements (like L-section profiles) with large dimensions and therefore the transverse stiffness is not negligible: these elements are joined to the longitudinal elements by welding. For this reason the theories stated above, which do not consider the bending stiffness and the schematization of the joint components like a pin, are approximate. By virtue of these factors, after a preliminary design of the basic module, the next step consisted in the realization of the solid model and subsequent finite element analyses (FEM). Fig. 5 shows the basic module. It was studied using S355 J2 (UNI EN 10027-1) carbon steel whose main mechanical characteristics, for thickness less than or equal to $16 \mathrm{~mm}$, are the following:

$\sigma_{R}=510 \div 680 \frac{\mathrm{N}}{\mathrm{mm}^{2}}, \quad \sigma_{s n}=355 \frac{\mathrm{N}}{\mathrm{mm}^{2}}$ and $A \geq 22 \%$.

The module is composed of the following elements: $n^{\circ} 4$ current L-profiles $160 \times 160 \times 16$ according to UNI EN 10056; $n^{\circ} 8$ diagonals L-profiles $100 \times 100 \times 13$ according to UNI EN 10056 and 
$\mathrm{n}^{\circ} 12$ uprights L-profiles $60 \times 60 \times 10$ according to UNI EN 10056. Figure 5 shows its geometry. The length of the boom is $80 \mathrm{~m}$ so, with reference to the size of the basic module, it will be composed by No. 15 basic modules to which are added two additional modules. The length of each additional module is $2.5 \mathrm{~m}$, one for the top and one for the base of boom. The tower will be made of No. 8 basic modules because its length is $45 \mathrm{~m}$. An additional module, whose length is 5 $\mathrm{m}$, will be applied to the top of the tower.

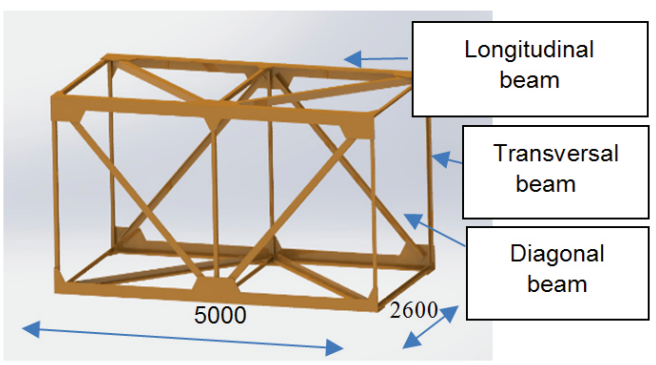

Figure 5: Basic module of the structure $(\mathrm{mm})$

No. 10 basic modules with two supplementary identical modules will compose the two $55 \mathrm{~m}$ length tie-rods in order to constrain them to the

top of the tower and to the base of the foundation plinth (Figure 6).

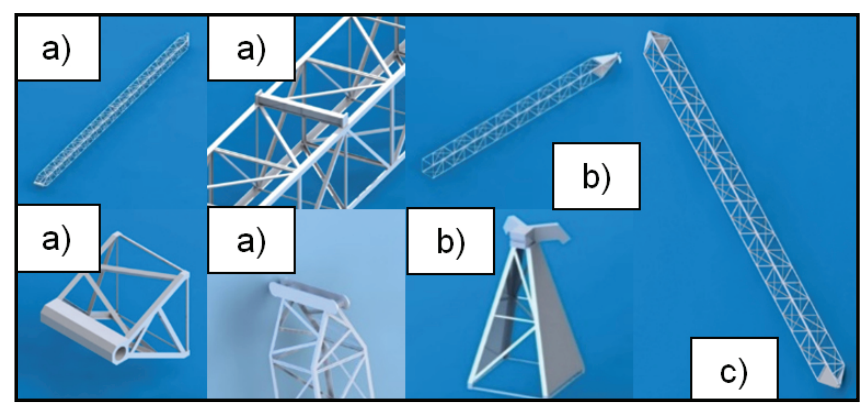

Figure 6: a): Boom; b): Tower and c): Tie rod

There are two ropes used by the crane: the first one for boom hoisting, the second one for load hoisting. For standardization and economic reasons, it was chosen a unique type of rope, varying the number of pulleys in order to compensate the considerably different load magnitude for the two different movements (one for the load and one for the boom). Figure 7 shows the schematization of the ropes. It is important to observe that for the movement of the boom, No. 17 pulleys are necessary while for move the load only No. 9 pulleys are necessary. The maximum load acting on the rope was determined considering the friction, both for the rope and for the pulley. The value of the friction coefficient is 0.98 (UNI EN 13001-3-2). By means of the next formula it is possible to evaluate the maximum load acting on each rope.

For the boom hoisting:

$F g=F f \frac{1-\eta^{n+1}}{1-\eta} \approx F f * 13.8$

For the payload hoisting:

$F g=F f \eta \frac{1-\eta^{n}}{1-\eta} \approx F f * 7.3$
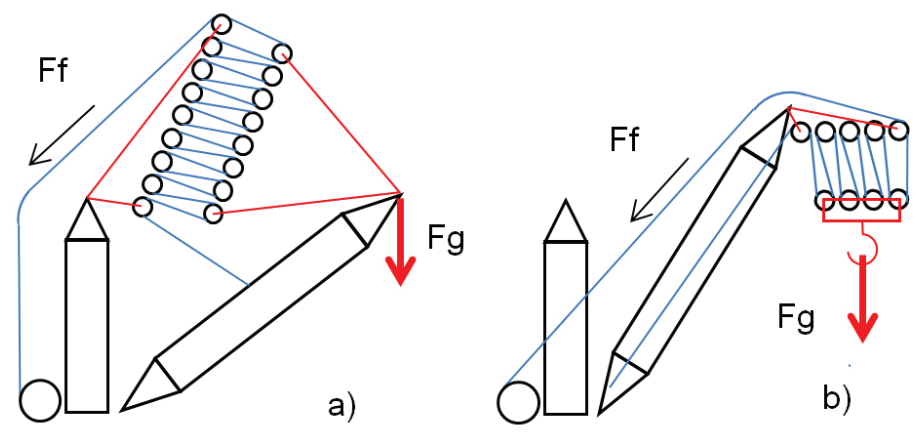

Figure 7: Two ropes schematization for hoisting: a) boom; b) payload 
According to the considerations stated above the rope chosen is $6 \times 36$ Warrington-Seale with a 24-mm diameter.

\section{SOLID MODEL AND FEM ANALYSES}

Figure 8 shows the schematizations used for analyses; obviously, they refer to the three con- figurations that appear to be the most important in the load chart of the crane. The stiffness of each spring, which represents the rope in the fem model, was evaluated by the length of the rope and the number of the pulleys. These values are reported in Table 1.

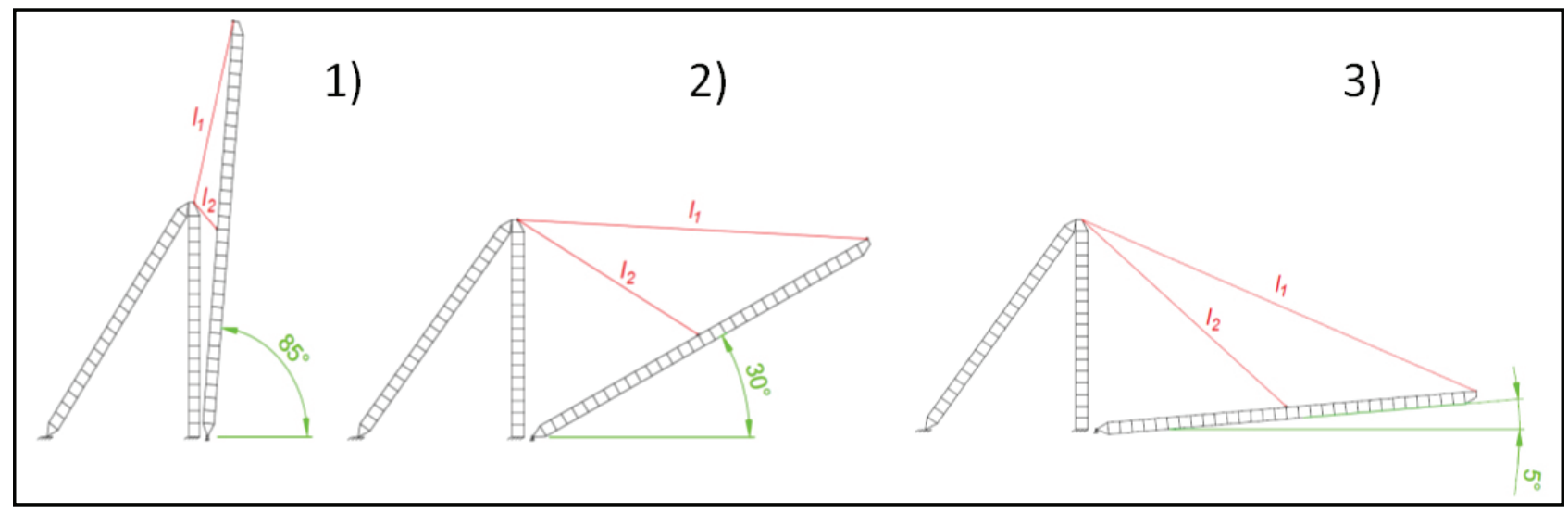

Figure 8: Different geometrical configurations developed for numerical analyses

Table 1: Stiffness values for different geometrical configurations

\begin{tabular}{|c|c||c|c|}
\hline Configurations & 1 & 2 & 3 \\
\hline $\mathrm{K} 1[\mathrm{~N} / \mathrm{mm}]$ & 26200 & 13100 & 10300 \\
\hline $\mathrm{K} 2[\mathrm{~N} / \mathrm{mm}]$ & 9150 & 1350 & 1000 \\
\hline
\end{tabular}

\section{DESCRIPTION OF FEM MODEL}

The analyses may be performed by concentrated parameter models like in [06, 09, 19], but in this work the analyses were carried out by FEM analyses. In particular, FEM analyses were performed by Autodesk Mechanical Simulation software and the FEM model is composed of about 100.000 quadratic beam elements. The first numerical analyses performed are static analysis considering an increase of the nominal load equal to 1.2 as it was indicated in the Standard (EN 13001) and in the bibliography [15]. In addition to the payload, the load was increased of $5 \mathrm{t}$ considering the weight of both the hoist hook and the related pulleys on it. According to these assumptions, the load applied in the configuration with $60 \mathrm{t}$ becomes equal to $78 \mathrm{t}$, while in the configuration with $30 \mathrm{t}$ becomes equal to $42 \mathrm{t}$.
The machine is also subject to the wind action. The magnitude of this load may be evaluated in two different ways. The first one, also used in the Standards, involves the application of a static equivalent force that depends essentially on the wind pressure (which is related to the wind speed), the frontal area of the elements and by certain coefficients. In this approach it is fundamental to correctly define the values of these coefficients, which strongly influence the wind action [17]. The second approach, much more complex, involves the study of the wind - structure interactions, based on the dynamic performance of the structure itself [02]. The first approach is used in this work applying a maximum wind velocity equal to $25 \mathrm{~m} / \mathrm{s}$. This value is derived from the place of installation of the crane, which is in a small valley. Figure 9 shows typical results from FEM analyses.

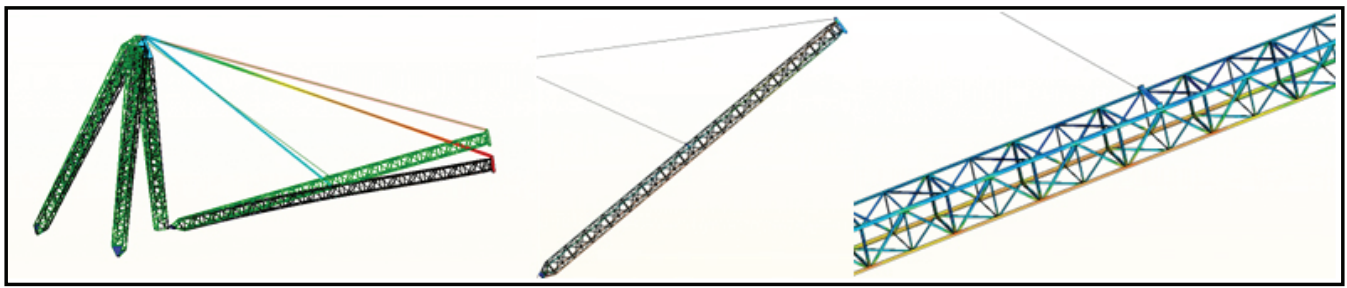

Figure 9: Displacement and Von Mises equivalent stress in the second geometrical configuration $\left(30^{\circ}\right)$ 
The maximum stress magnitude is localized near the base of the boom, the values of the equivalent Von Mises stress are $150 \mathrm{MPa}, 195 \mathrm{MPa}$ and $175 \mathrm{MPa}$ respectively for three different geometrical configurations reported in Figure 8.

The maximum displacements are at the top of the boom and they are worth approximately 180 $\mathrm{mm}, 370 \mathrm{~mm}$ and $330 \mathrm{~mm}$, respectively for the geometrical configurations 1,2 and 3 . The safety factor as to the yield strength of the steel used for the design of the crane (S355 J2 according to UNI EN 10027-1) is about 1.8. The fatigue phenomena was not considered for two reasons. The first motivation is correlated to the load spectrum factor which is very low $\left(\mathrm{K}_{\mathrm{sp}}=0.5\right)$ due to the size variability of the marble blocks; the second one is correlated to the number of hoisting cycles as- sumed equal to 6000 (three cycles a day for 200 days in 10 years) which are very low.

\section{MODAL ANALYSIS}

Many different modal analyses were carried out in order to evaluate the fundamental natural frequencies of the crane. The first objective is to assess the structural response under time-variable actions by using the principle of modal superposition. The second one is to study the dynamic behavior of the structure in relation, for instance, to the wind structure interaction effects [02] or load conditions induced by seismic activity [11, 13]. The analyses were conducted for all three geometrical configurations of the structure and the results are shown in Figure 10 and in Table 2 for the first geometrical configuration.
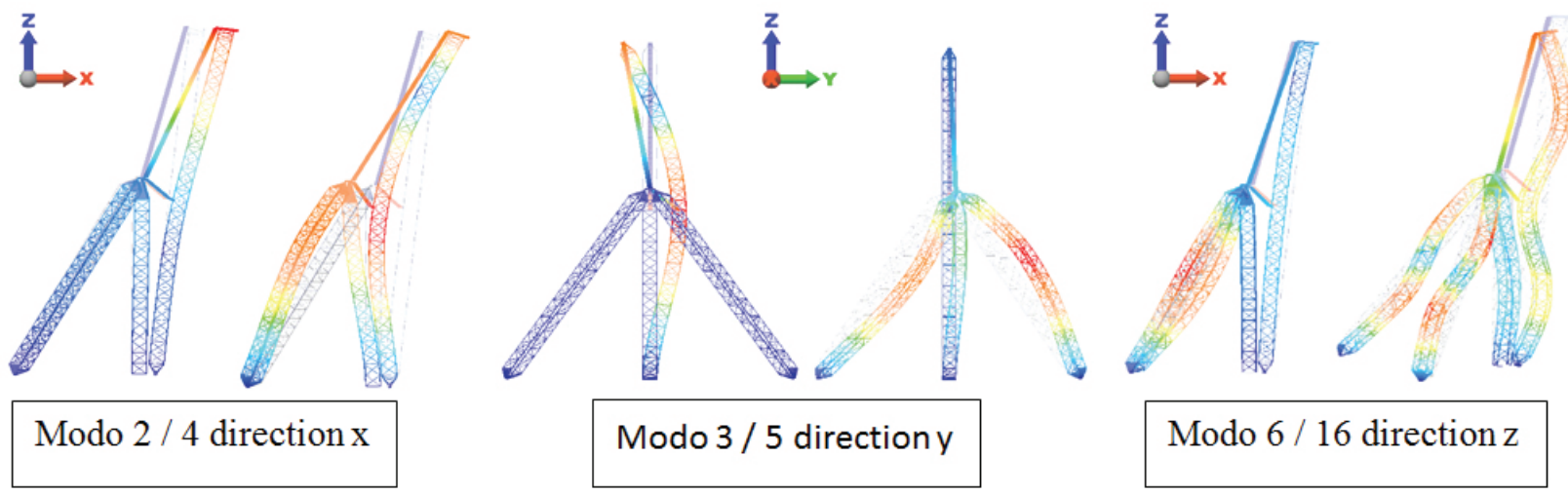

Figure 10: Deformation of the structure in the first mode of vibrations

Table 2: Natural frequencies and mass participation factor

\begin{tabular}{|c|c|c|c|}
\hline Mode & Freq. [Hz] & \% Mass & \%Cumulative \\
\hline $2-x$ & 1.96 & 23.35 & 23.35 \\
\hline $4-x$ & 3.43 & 46.43 & 69.78 \\
\hline $3-y$ & 2.81 & 6.43 & 27.45 \\
\hline $5-y$ & 4.24 & 36.51 & 63.96 \\
\hline $6-z$ & 4.81 & 6.10 & 9.38 \\
\hline $16-z$ & 13.86 & 21.91 & 38.66 \\
\hline
\end{tabular}

Like previous analyses, the structure was studied in other two different configurations. Specifically, the analyses showed that in the transverse plane, i.e. according to the y-direction, the frequencies are very low since, in this direction the boom is virtually bound only at the base. The analyses conducted on singular elements (tie rod, boom and column) and on the whole structure confirm the above results, i.e. the natural frequencies are very low. For instance, the structure composed only of the tower and the tie rod shows similar frequencies in all three directions whose values are near to $4 \mathrm{~Hz}$.

\section{DYNAMIC ANALYSIS}

The study of the dynamic behavior of the crane, in case the structure is subject to time variable actions, may be reliable only if the magnitude of damping is well defined. From literature and from experimental tests carried out on similar structures, the damping value changes from $0.5 \%$ to $10 \%$ for bolted steel structures. The value depends both on the material (internal friction) and on the type of joint between different elements which compose the structure [01, 04]. In this work, the value adopted is equal to $0.5 \%$ (in 
order to increase the safety factor). The method used for numerical solution developed in the finite element analyses is the direct integration method. This methodology may be expressed by the next equation $[07,08]$ :

$$
[M]\{\ddot{D}\}_{n}+[C]\{\dot{D}\}_{n}+[K]\{D\}_{n}=\left\{R^{\text {ext }}\right\}_{n}
$$

Where the subscript $\mathrm{n}$ is the time instant.

[M] is the mass matrix;

$[\mathrm{C}]$ is the damping matrix;

$[\mathrm{K}]$ is the stiffness matrix;

$\{D\}$ is the nodal displacement vector;

$\left\{R^{\text {ext }}\right\}$ is the external actions vector.

The Autodesk Mechanical Simulation software used for numerical analyses adopts direct integration procedure of the Newmark- $\beta$ method (implicit method) which assumes a linear variation of the acceleration during the time interval $\Delta t$ and uses two interpolation parameters ( $\gamma$ and $\varphi)$ to choose the acceleration used in the solution. The equations for numerical solution are [07, 08]:

$$
\begin{gathered}
\{D\}_{n+1}=\{D\}_{n}+\Delta t\{\dot{D}\}_{n}+\frac{\Delta t^{2}}{2}\left[(1-2 \varphi)\{\ddot{D}\}_{n}+2 \varphi\{\ddot{D}\}_{n+1}\right] \\
\{\dot{D}\}_{n+1}=\{D\}_{n}+\Delta t\left[(1-\gamma)\{\ddot{D}\}_{n}+\gamma\{\ddot{D}\}_{n+1}\right]
\end{gathered}
$$

The damping matrix in equation 3 , can be written in the following way:

$$
[C]=\alpha[M]+\beta[K]
$$

Where $\alpha$ and $\beta$ are the Rayleigh damping variables. These values, which may be preliminarily estimated by literature, are a function of the frequencies considered in the analysis. In this paper, $\alpha$ and $\beta$ values were determined iteratively calculating the displacement of the structure due to a specific time depending on load actions. The value of the damping is determined numerically by logarithmic decrement also called free decay method [18] (by the displacement diagram), and compared with imposed value.

In general the displacement in the single degree of freedom can be represented by this formula:

$x(t)=e^{-\xi \omega t}\left(\mathrm{~A} * \cos \left(\omega_{d} t\right)+\mathrm{B} * \sin \left(\omega_{d} t\right)\right)$

Where:

$\omega$ is the undamped natural frequency;

$\omega_{d}=\omega^{*} \sqrt{ }\left(1-\xi^{2}\right)$ is the damped natural frequency;
$A ; B$ are constants that depend on the initial conditions;

$\xi$ is the system damping.

The decrement logarithm $\delta$ is defined by ratio between two subsequent peaks of $x_{(t)}$ function.

$$
\delta=\ln \left\{\frac{x\left(t_{1}\right)}{x\left(t_{2}\right)}\right\}=\frac{2 \pi \xi}{\sqrt{1-\xi^{2}}}
$$

The numerical analyses carried out showed that the magnitude of Rayleigh damping variables depend on the crane geometrical configuration although their changes are extremely limited; the values assumed are $\alpha=1.5$ and $\beta=0.001$. In order to evaluate the dynamic behavior of the crane numerical different patterns load were simulated. This paper shows the results relating to the load applying the pattern in Figure 11. It is a trapezoidal pattern in which a different velocity of load application is imposed (the control is generally carried out by a frequency converter). This moving load pattern shows a constant segment also in order to evaluate the attenuation of the accelerations and a descending segment relative to a sudden load release or rupture of the load restraining system; this is the classical pattern for this type of study [05]. Figure 12 and Figure 13 show the results for the first geometrical configuration $\left(85^{\circ}\right)$, while Figure 14 and Figure 15 for the third geometrical configuration $\left(30^{\circ}\right)$.

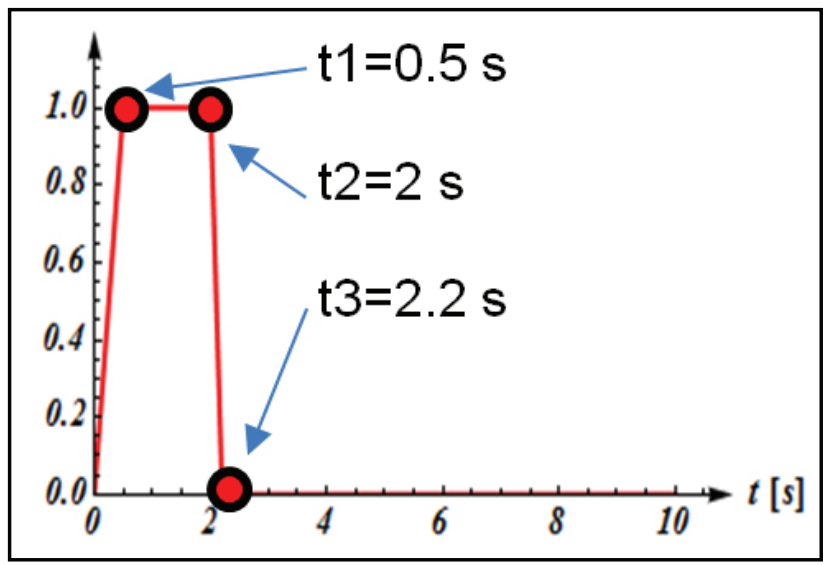

Figure 11: Speed pattern of moving load

\section{DISCUSSION}

According to the results synthetically stated above, it is clear that the most critical geometrical configuration both for the accelerations and for the displacements at the end of the boom is when the angle of the boom, with respect to the horizontal plane, is equal to $30^{\circ}$. 

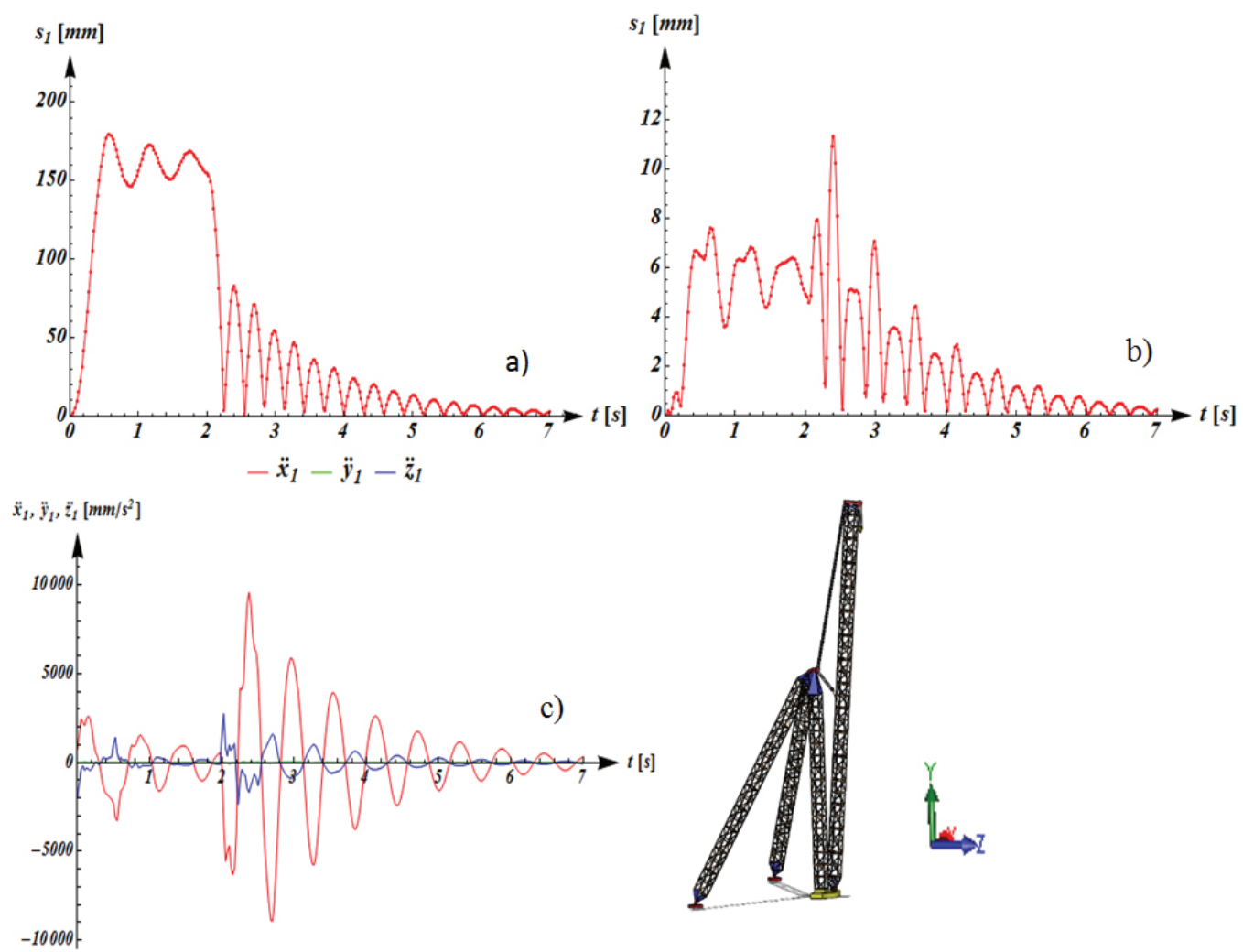

Figure 12: Displacement magnitude at the end of the boom a) and at the end of the tower b), acceleration at the end of the boom c), geometrical configuration with the angle equal to $85^{\circ}$.

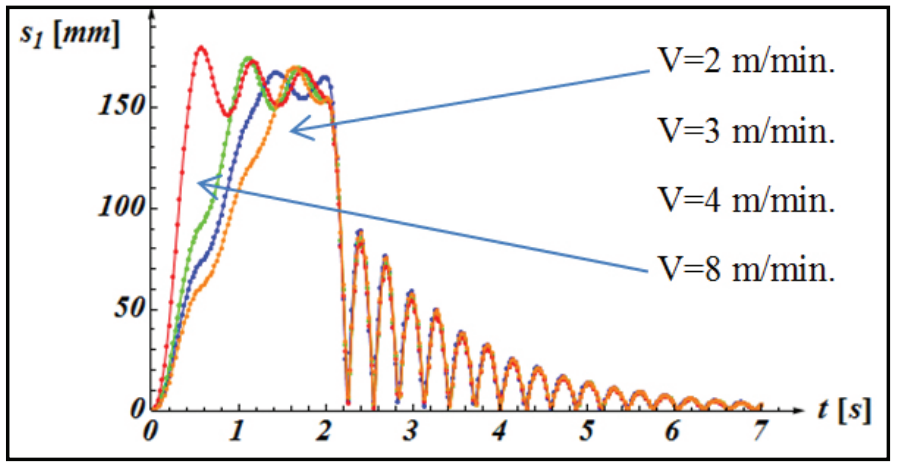

Figure 13: Displacement magnitude at the end of the boom [mm] in function of the different load application velocity, geometrical configuration with the angle equal to $85^{\circ}$.

The acceleration and displacement magnitude is approximately twice the amount in the $85^{\circ}$ geometrical configuration. They are closely related, in a proportional way, to the load application velocity. The release of the load or the rupture of the load restraining system generates much higher dynamic actions compared to the ones which can be induced in the structure in case of different load application patterns. The overall assessment of the boom is fundamental; through the analyses carried out it is possible to state that the most critical condition for the boom is the buckling phenomenon in the transversal plane. This phenomenon is also the most dan- gerous in other big structures like a bridge [14]. The safety factor as to buckling phenomena is determined considering the total loads, including the inertial one, and is approximately 1.3 while the safety factor as to yield point of the material assumed for making the structure is about 1.8. Figure 16 shows the derrick crane which was built and positioned in the quarry ready for handling the marble blocks.

\section{CONCLUSION}

In this research a very big derrick crane for size and payload was studied and designed considering the dynamical actions induced by different 
moving load patterns. The research was developed through analytical and numerical analyses. The crane was preliminarily designed by analytical schemes and subsequently the crane dy- namical behavior was studied by Fem analyses. The natural frequencies of the crane, in different geometrical configurations, are comparable with those in other types of cranes.
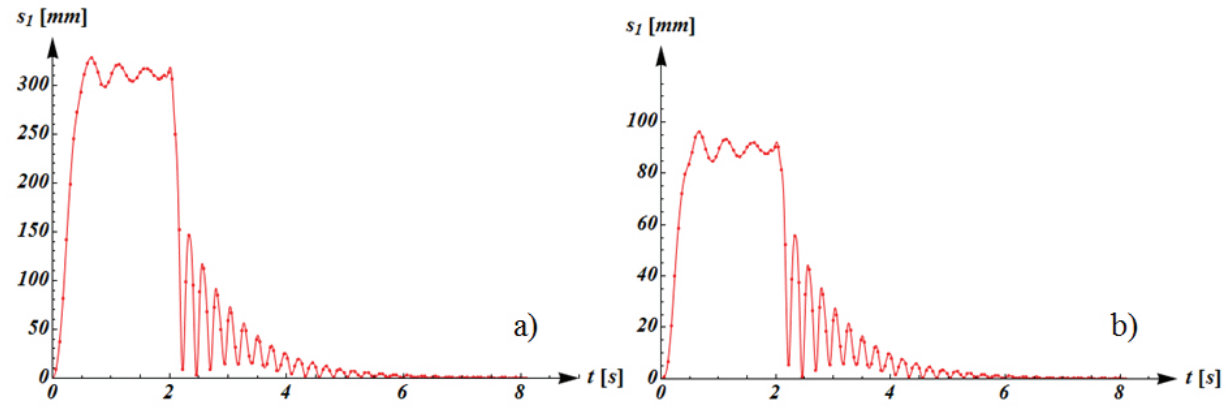

$-\ddot{x}_{1}-\ddot{y}_{1}-\ddot{z}_{1}$
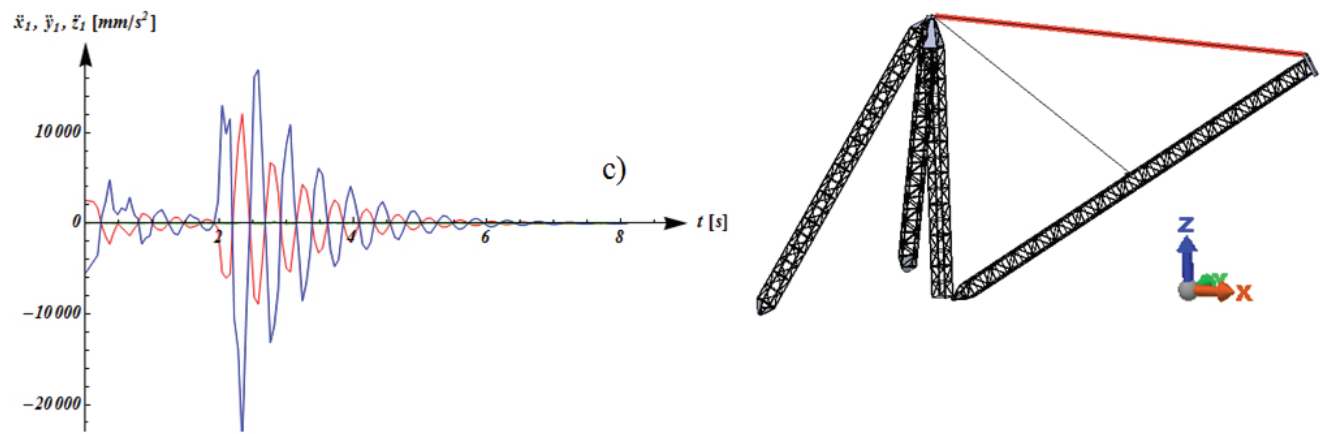

Figure 14: Displacement magnitude at the end of the boom a) and at the end of the tower b), acceleration at the end of the boom c), geometrical configuration with the angle equal to $30^{\circ}$

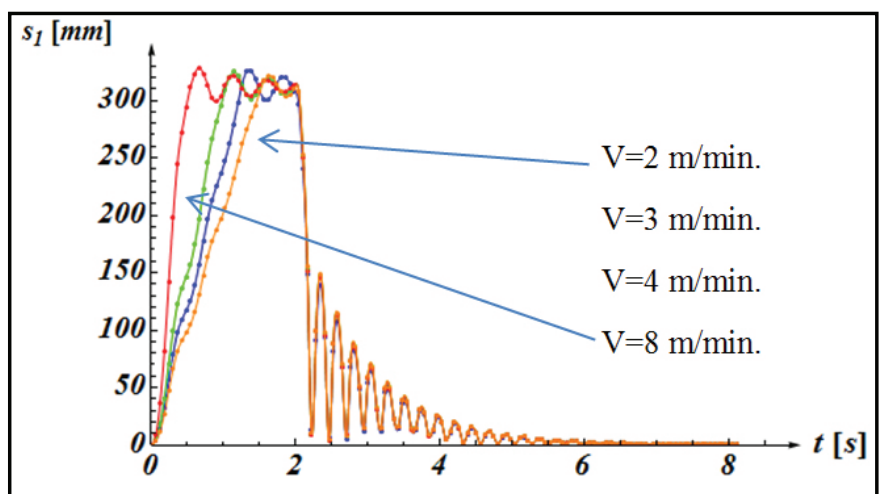

Figure 15: Displacement magnitude at the end of the boom [mm] in function of the different load application velocity, configuration with the angle equal to $30^{\circ}$

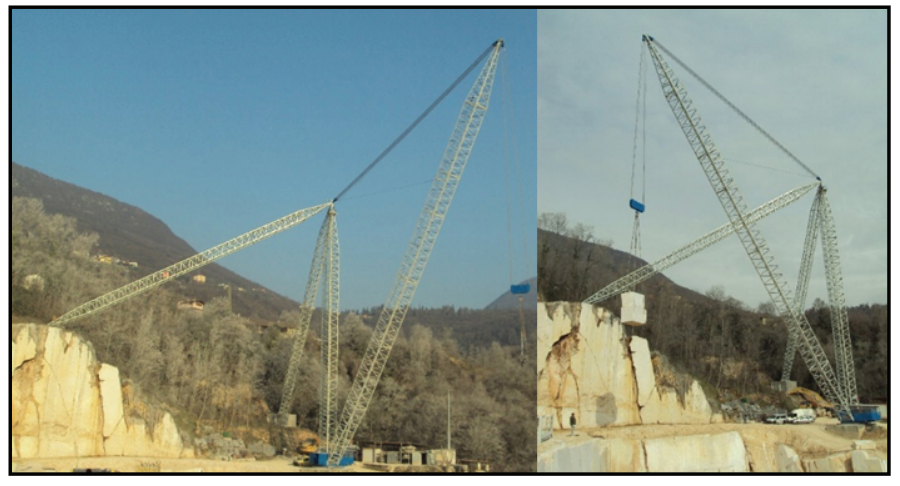

Figure 16: The derrick crane 
In order to study how the load handling influences the dynamical actions on the crane, many numerical analyses were carried out by implementing different moving load patterns. The results show that, regardless of the geometric configuration of the crane, the sudden load release condition is the one that causes the greatest magnitude of dynamic action. The development of research is for two aspects. The first point of view concerns the boom weight reduction (the entire boom or a portion of it) using high strength steels, aluminum alloys or composite materials. This development applied to other lifting equipment or industrial vehicle shows good and promising results $[12,16]$. The main object is to lighten the moving part of the structure to decrease the size of accessories like ropes and boom actuation system (engines and gearboxes). The second point of view is to study technological and constructive solutions to increase the safety factor for buckling phenomena and therefore optimizing the structure. The buckling phenomenon is the most critical structural condition for this type of crane and especially for the boom; in fact, this was the main reason behind the failure of the boom positioned on similar crane.

\section{ACKNOWLEDGEMENT}

The authors want to give special thanks to Eng. Andrea Morabito for the valuable support given in this research.

\section{REFERENCES}

1) Blanter, M.S., Golovin, I.S., Neuhäuser, H., Sinning,H.R. (2007) Internal friction in metallic materials, New York: Springer Berlin, ISBN-10 3-540-68757-2.

2) Bošnjak, S., Zrnić, N. (2009). Dynamic response of mobile elevating work platform under wind excitation, J. of Mechanical Engineering, Vol. 55, pp.104-113.

3) Chen, E. W. F., Lui, M. (2004) Handbook of structural engineering, Library of Congress, ISBN: 0-8493-1569-7.

4) Chen, G. (2014) Handbook of friction and vibration interaction, Woodhead Publishing Limited, ISBN 978-0-85709-458-2.

5) Gašić, V., Zrnić, N., Milovančević, M. (2013). Consideration of various moving load models in structural dynamics of large gantry crane, FME Transactions, Vol. 41, pp.311-316.

6) Gašić, V., Zrnić, N., Obradović, A., Bošnjak, S. (2011). Consideration of moving oscillator problem in dynamic response of bridge cranes, FME Transactions, Vol. 39, pp. 17-24.
7) Gerardin, M.,Rixen D.J. (2015) Mechanical vibration theory and application to structural dynamics 3 3th edition, John Wiley and Sons Inc., ISBN : 978-1-118-90020-8.

8) Girard, A., Roy, N. (2003) Structural dynamics in industry, Great Britain: John Wiley and Sons Inc., ISBN : 978-1-84821-004-

9) Incerti, G., Solazzi, L., Petrogalli, C. (2015). Lumped parameter models for numerical simulation of the dynamic response of hoisting appliances. ICSEMA 2015, 17th International Conference on Systems Engineering Modelling and Analysis, November 9-10 2015, Venice, Italy.

10) Shapiro, L., Shapiro, J. (2011) Cranes and derricks, 4th edition, McGraw-Hill Professional, ISBN: 978-0-07-162558-6.

11) Solazzi, L. (2011). Ship to shore crane subject to earthquake, Procedia Engineering, Vol. 10 pp. 2690-2695.

12) Solazzi, L. (2012). Applied research for Weight Reduction of an industrial Trailer, FME Transactions, Vol. 40, pp. 57-62.

13) Solazzi, L. (2013). Evaluating the seismic effects on lifting equipment, XI International Conference on Recent Advances in Structural Dynamics (RASD 2013), 1-3 July, Pisa, Italy.

14) Solazzi, L. (2015). Innovative bolted junction with high ductility for circular tubular element; Journal of Constructional Steel Research vol. 112, pp. 175-182.

15) Solazzi, L., Incerti, G., Petrogalli, C. (2014). Estimation of the dynamic effect in the lifting operations of a boom crane, Proceedings of the 28th European Conference on modelling and simulation, 27/05-30/05 2014, Brescia, Italy.

16) Solazzi, L., Scalmana, R. (2012). New Design Concept for a Lifting Platform made of Composite Material, Applied Composite Materials, An International Journal for Science and Application of Composite Materials, ISSN 0929-189X Appl Compos Mater DOI 10.1007/s10443-012-9287-2.

17) Solazzi, L., Zrnić, N. (2016). Numerical study of wind actions applied to a low profile container crane, FME Transactions, Vol. 44, pp. 29-35.

18) Thorby, D. (2008) Structural dynamics and vibration in practice, an engineering hand book, Elsevier, ISBN : 978-0-7506-8002-8.

19) Zrnić, N., Gašić, V., Bošnjak, S., Đorđević, M. (2013). Moving load in structural dynamics of crane: bridging the gap between theoretical and practical researches, FME Transactions, Vol. 41, pp. 291-297.

Paper sent to revision: 28.09.2016.

Paper ready for publication: 03.03.2017. 